\title{
Adolescent Running Biomechanics - Implications for Injury Prevention and Rehabilitation
}

\author{
Simon C. McSweeney ${ }^{1}$, Karin Grävare Silbernagel ${ }^{2}$, Allison H. Gruber ${ }^{3}$, \\ Bryan C. Heiderscheit ${ }^{4}$, Brian J. Krabak ${ }^{5}$, Mitchell J. Rauh ${ }^{6}$, Adam S. Tenforde ${ }^{7}$, \\ Scott C. Wearing ${ }^{1}$, Astrid Zech ${ }^{8}$ and Karsten Hollander ${ }^{9 *}$
}

${ }^{1}$ School of Clinical Sciences, Faculty of Health, Queensland University of Technology, Brisbane, QLD, Australia, ${ }^{2}$ Department of Physical Therapy University of Delaware, Newark, NJ, United States, ${ }^{3}$ Department of Kinesiology, School of Public Health - Bloomington, Indiana University, Bloomington, IN, United States, ${ }^{4}$ Department of Orthopedics and Rehabilitation, University of Wisconsin, Madison, WI, United States, ${ }^{5}$ Department of Rehabilitation, Orthopedics and Sports Medicine, University of Washington and Seattle Childrens Hospital, Seattle, WA, United States, ${ }^{6}$ Doctor of Physical Therapy Program, San Diego State University, San Diego, CA, United States, ${ }^{7}$ Department of Physical Medicine and Rehabilitation, Harvard Medical School, Spaulding Rehabilitation Hospital, Boston, MA, United States, ${ }^{8}$ Department of Human Movement Science and Exercise Physiology, Institute of Sport Science, Friedrich Schiller University Jena, Jena, Germany, ${ }^{9}$ Institute of Interdisciplinary Exercise Science and Sports Medicine, Faculty of Medicine, MSH Medical School Hamburg. Hamburg, Germany

\section{OPEN ACCESS}

Edited by:

Thomas Neri,

Centre Hospitalier Universitaire (CHU) de Saint-Étienne, France

Reviewed by:

Allan Munro,

University of Salford, United Kingdom Richard Arthur Brindle, Keller Army Community Hospital, United States

*Correspondence: Karsten Hollander karsten.hollander @medicalschool-hamburg.de

Specialty section

This article was submitted to Injury Prevention and Rehabilitation, a section of the journal

Frontiers in Sports and Active Living

Received: 01 April 2021

Accepted: 23 July 2021

Published: 26 August 2021

Citation:

McSweeney SC, Grävare

Silbernagel K, Gruber AH, Heiderscheit BC, Krabak BJ, Rauh MJ, Tenforde AS, Wearing SC, Zech A and Hollander K (2021) Adolescent Running Biomechanics - Implications for Injury Prevention and Rehabilitation

Front. Sports Act. Living 3:689846. doi: 10.3389/fspor.2021.689846
Global participation in running continues to increase, especially amongst adolescents. Consequently, the number of running-related injuries (RRI) in adolescents is rising. Emerging evidence now suggests that overuse type injuries involving growing bone (e.g., bone stress injuries) and soft tissues (e.g., tendinopathies) predominate in adolescents that participate in running-related sports. Associations between running biomechanics and overuse injuries have been widely studied in adults, however, relatively little research has comparatively targeted running biomechanics in adolescents. Moreover, available literature on injury prevention and rehabilitation for adolescent runners is limited, and there is a tendency to generalize adult literature to adolescent populations despite pertinent considerations regarding growth-related changes unique to these athletes. This perspective article provides commentary and expert opinion surrounding the state of knowledge and future directions for research in adolescent running biomechanics, injury prevention and supplemental training.

Keywords: biomechanical, youth, running-related injuries, kinetics, kinematics, footstrike pattern

\section{INTRODUCTION}

Youth running participation is increasing throughout the world, with global participation rates of adolescents reported among the top three sport activities in most regions (Hulteen et al., 2017). Adolescents are defined by the World Health Organization as individuals aged 10-19 years (World Health Organization, 2018). However, the "biological" age or maturational development of adolescent athletes may be of greater significance with respect to running-related injuries (RRI). Changes in tissues such as bone, tendon, muscle, cartilage and growth plate occur at varied rates and locations during times of rapid growth (Lloyd et al., 2014; Krabak et al., 2016a). Maturation of these tissues during puberty is affected by hormonal, genetic and environmental factors which may collectively influence running biomechanics, load tolerance and RRI in youth runners (Malina, 1994; Lloyd et al., 2014; United States track field, 2020). Notably, early sport specialization in adolescent athletes is associated with 
increased sport-related injury risk, attributed in part to the homogeneity of movement patterns repetitively stressing the same immature tissues (Hamill et al., 2012; Post et al., 2017). Although associations between running biomechanics and overuse injuries have been widely studied in adults (Ceyssens et al., 2019; Hollander et al., 2021a), comparatively little research has targeted potential relationships between musculoskeletal injury and growth-related changes in biological age, body anthropometry, neuromuscular control, and running biomechanics in youth (Krabak et al., 2020). The aim of this perspective article was to provide a brief summary of the current epidemiology and etiology of RRI. Special consideration is given to the transition in physiological characteristics (such as bone mineral content) that occur around puberty. We subsequently discuss how growth, maturation and sex may all influence running biomechanics, tissue load and RRI risk in adolescent athletes.

\section{EPIDEMIOLOGY AND ETIOLOGY OF RUNNING-RELATED INJURIES IN ADOLESCENTS}

The growth in participation in youth running has seen a parallel increase in the incidence of RRI in adolescents (Mehl et al., 2011). Prospective studies of high school cross-country runners have reported a wide range in the cumulative seasonal incidence of RRI for girls (34\% to $47 \%$, corresponding to 16.7 to 19.6 per 1000 athletic exposures [AEs]) and boys (26\% to $48 \%$, corresponding to 0.9 to 15.0 per 1000 AEs) (Beachy et al., 1997; Rauh et al., 2000, 2006). The most commonly injured body locations for high school cross-country runners for both sexes are the shin and knee (Rauh et al., 2000, 2006). Among middle school crosscountry runners, the incidence of RRI injuries has been observed at 10.9 per 1000 AEs and 8.0 per 1000 AEs for girls and boys, respectively (Beachy and Rauh, 2014). A cross-sectional study involving 2,113 middle school runners (average age 13.2) found self-reported RRI were more prevalent in girls than boys $(56 \%$ vs. $50 \%, p=0.007$ ) (Wu et al., 2021). Girls reported more ankle sprains, patellofemoral pain and shin splints than boys, while boys more frequently reported plantar fasciitis, iliotibial band syndrome and Osgood-Schlatter Disease (Wu et al., 2021) than girls. A separate report in this cohort identified bone stress injury (BSI) was more common in girls than boys $(6.7 \%$ vs. $3.8 \%, p=$ 0.004 ) with the tibia, metatarsus and fibula the most common anatomical locations of injury (Tenforde et al., 2021).

Understanding the etiology, treatment, and prevention of RRI requires identifying associated intrinsic and extrinsic risk factors (Meeuwisse, 1994; Bahr and Holme, 2003; Rauh et al., 2011). A recent consensus statement on youth runners provided a comprehensive evaluation of risk factors and their relationships with musculoskeletal injuries from prospective cohort and retrospective studies (Krabak et al., 2020). Previous injury (Rauh et al., 2000, 2006; Plisky et al., 2007; Reinking et al., 2010; Tenforde et al., 2013; Tirabassi et al., 2016) and sex (female) have been the most consistent intrinsic risk factors for RRI among adolescent runners
(Rauh et al., 2000, 2006; Plisky et al., 2007; Tenforde et al., 2013; Tirabassi et al., 2016; Hollander et al., 2021b). Other frequently examined intrinsic risk factors significantly related to RRI include muscle weakness (hip abductor, knee extensors and flexors) (Luedke et al., 2015), Q-angle $>20$ degrees (Rauh et al., 2007), increased hip internal rotation range of motion (Yagi et al., 2013), and leg-length inequality greater than $1.5 \mathrm{~cm}$ (Rauh, 2018). In female adolescent runners, menstrual dysfunction (Barrack et al., 2014; Rauh et al., 2014) and low bone mineral density (Barrack et al., 2014; Rauh et al., 2014) have been significantly associated with RRI and are the best established risk factors for BSI. Furthermore, it has been shown that risk for BSI is related to the number of accumulated risk factors (Tenforde et al., 2013; Barrack et al., 2014).

To date, there are several extrinsic risk factors that have been identified that contribute to RRI in high school crosscountry runners. These include low step rate (Luedke et al., 2016), higher weekly mileage (Tenforde et al., 2011), and infrequently alternating short and long training mileage or running predominantly on hills during summer months (Rauh, 2014). While a recent study indicated that female high school cross-country runners who were classified as high sport specializers were at a two-fold greater risk of musculoskeletal RRI than female high school runners classified as low sport specializers (Rauh et al., 2018), Garcia et al. found no association between sport specialization and RRI among male and female high-and middle-school cross-country runners (Garcia et al., 2021). The differences may be in part due to differing study designs, sample of runners, and injury definitions (Rauh et al., 2018; Garcia et al., 2021).

\section{ADOLESCENT RUNNING BIOMECHANICS}

\section{Kinetics and Temporospatial Variables}

It is generally assumed that the kinetics and temporospatial metrics of adolescents during running are largely similar to adult runners when effects of body height and mass are removed. This assertion, however, has not been tested due to the limited studies describing these metrics in adolescent runners.

As age increases, step length during running increases while step rate decreases (Schepens et al., 1998). The increased step length is attributed to the age-associated increase in leg length (Schepens et al., 1998) as a longer leg length has been associated with lower habitual step rate in adult runners (Tenforde et al., 2019). Prior to the age of 12 years, the decrease in step rate is associated with a decrease in the mass-specific whole body vertical stiffness (ratio of vertical ground reaction force and vertical displacement of the center of mass) due to an increase in body mass with a constant stiffness (Schepens et al., 1998). However, from 12 to 18 years of age, vertical stiffness and step rate are approximately constant due to a parallel increase in both stiffness and mass with age (Schepens et al., 1998).

As running speed increases, not surprisingly, both step rate and length increase, regardless of age. Of note, despite maximum running speed increasing with adolescent age, the relative contributions of step rate and step length to maximum speed change with age or more precisely maturity. In those 
not yet achieving peak height velocity (an indicator of skeletal maturity), maximum running speed was best predicted by step rate, while step length was the key factor in those post-peak height velocity (Meyers et al., 2017). In adolescents near and above peak height velocity, step rate and horizontal propulsive force during maximum speed running remain relatively constant across age (Schepens et al., 1998; Rumpf et al., 2015). Additionally, greater peak vertical ground reaction force during maximum speed running is evident in older versus younger adolescents even when accounting for the increased body mass (Rumpf et al., 2015). Kinetic and temporospatial measures commonly described in adult runners, such as horizontal braking force, vertical loading rate, and step width, have not been characterized in adolescent distance runners.

\section{Footstrike Mechanics and Kinematics}

Most habitually shod adolescents make initial contact with a rearfoot strike [i.e., initial contact with the heel (Hoenig et al., 2020)] when running at slower speeds (Hollander et al., 2018; Latorre Roman et al., 2019). However, the prevalence of rearfoot strike patterns depend on running speed, the use of and habituation to footwear, age and sex (Hollander et al., 2018). Non-rearfoot strike patterns [i.e., making initial contact with the toes or midfoot (Hoenig et al., 2020)] have been advocated as a potential injury prevention strategy in adolescents and adults (Lieberman et al., 2010), although the evidence is conflicting especially for youth runners (Warr et al., 2015; Davis et al., 2017; Chan et al., 2018; Messier et al., 2018; Anderson et al., 2019; Krabak et al., 2020).

While decreasing loading rate is one arguable benefit of a non-rearfoot strike pattern (Lieberman et al., 2010; Davis et al., 2016), a non-rearfoot strike is not required to achieve low loading rates (Stiffler-Joachim et al., 2019) and the evidence associating high loading rates to RRI development in adults are conflicting (Zadpoor and Nikooyan, 2011; Bredeweg et al., 2013; Kuhman et al., 2016; Davis et al., 2017; Dudley et al., 2017; Messier et al., 2018). Moreover, the results from several studies note that the biomechanical benefit of specific footstrike patterns are conflicting (Stearne et al., 2014; Davis et al., 2016; Dudley et al., 2017), which has been supported by recent prospective injury studies in adults (Warr et al., 2015; Kuhman et al., 2016; Messier et al., 2018; Anderson et al., 2019). Other evidence from studies on adult runners suggest that footstrike more likely affects the risk of specific injuries, rather than one footstrike pattern being more or less injurious than another (Hollander et al., 2021a). Further research encompassing the effect of footstrike pattern on adolescent running gait relating to injury is warranted.

\section{IMPLICATIONS FOR PREVENTION OF RUNNING-RELATED INJURIES}

\section{Bone and Bone Mineral Content}

Peak bone mass accrual is achieved by early adulthood and is influenced by biomechanical stressors to bone along with other health characteristics (i.e., diet; body weight and lean tissue, and hormonal function). A review of the influence of sports participation on bone density and strength suggests that running is less osteogenic than sports involving higher ground reaction forces in multidirectional loading, such as European football (e.g., soccer) and basketball (Tenforde and Fredericson, 2011). Participation in ball sports for two or more years prior to puberty may promote higher bone content and stiffer, more fracture resistant bones (Milgrom et al., 2000) and reduce future risk for BSI in adolescence and adulthood (Fredericson et al., 2005; Tenforde et al., 2013, 2021).

Adequate bone adaptations according to loading biomechanics require appropriate nutrition, sleep and hormonal function. The Female Athlete Triad and Relative Energy Deficiency in Sport (De Souza et al., 2014; Mountjoy et al., 2018; Tenforde et al., 2020) describe the consequences of low energy availability (defined as inadequate caloric intake vs. energy exercise expenditure) on bone density and hormonal function (including menstrual dysfunction). Caloric needs may be significantly higher during growth and to meet demands of the sport of running (Krabak et al., 2020). In addition to promoting adequate energy availability, ensuring appropriate calcium from food and vitamin D supplementation may promote bone gains and reduce risk for BSI (Kelsey et al., 2007; Sonneville et al., 2012; Barrack et al., 2017). While not adequately studied in adolescent runners, sleep is critical to promote growth and reduce risk for injury and should be duly considered in future research specific to this cohort (Copenhaver and Diamond, 2017).

\section{Muscle}

Lower extremity muscle strength is generally regarded as an important component of RRI prevention programs. The underlying rationale being that muscle weakness leads to altered running mechanics and reduced tolerance to loading, thereby increasing one's risk of common joint and soft tissue injuries. However, lower extremity muscle weakness has not been consistently shown to contribute to injury in the youth runner, similar to findings involving adult runners (Thijs et al., 2011; Mucha et al., 2017). One prospective study's findings of greater injury risk among high school runners with weak hip abductors, knee extensors and knee flexors, Luedke et al. (2015) is contrasted by another study suggesting increased hip abductor strength and hip abduction to adduction strength ratio increases injury risk (Finnoff et al., 2011). Despite this uncertainty regarding muscle weakness and injury risk, injury prevention programs with elements of high intensity neuromuscular training, jumping, plyometrics and balance training have been successful in reducing sports injuries in youth athletes (e.g., basketball, soccer, football, volleyball) (Emery et al., 2005; Rössler et al., 2014; Richmond et al., 2016). Such studies have not been conducted in youth runners, so the effectiveness of these programs remains unknown. Among adult runners, prevention programs emphasizing general lower extremity strength training have not reduced injury incidence (Toresdahl et al., 2020), though a program focused on foot muscle strengthening led to a 2.4-fold lower injury rate (Taddei et al., 2020).

\section{Tendon}

Tendons transfer load between the muscle and bone, are important for efficient movement and provide a mechanical 
buffer to protect muscle (Roberts and Azizi, 2010; Konow et al., 2012). In running, high-stress tendons, such as the Achilles tendon, store and release energy with each stride like a spring. The better the Achilles tendon functions at this task, the better the economy of running (Alexander, 1990). Tendon dimensions are typically coupled closely to those of the corresponding muscle, and are optimized for efficient muscle contraction and movement (Ker et al., 1988; Alexander, 2002). Both tendon and muscle respond to mechanical loading by becoming larger and stronger (Kubo et al., 2001; Lambertz et al., 2003). In youth, the muscle fascicles and tendon lengthen proportionally during maturation, as does tendon cross-sectional area and the physiological crosssectional area of muscle (O'Brien et al., 2010). However, the time course of adaptation may be very different (Mersmann et al., 2017), as one study has reported a lag of 1-2 months in tendon property response to resistance training in healthy adults (Kubo et al., 2010). The concern during adolescence is that there seems to be an even greater imbalance in the time course of growth between tendon and muscle properties (Mersmann et al., 2017). Load bearing tendons respond to load by improving their material properties (i.e., elastic modulus; tensile strength) in early adolescence, with hypertrophy (i.e., cross-sectional area change) occurring in the later stages of adolescents (Waugh et al., 2012; Mogi, 2020). The muscle, on the other hand, develops progressively during adolescence and this theoretical lag in tendon adaptation, especially in size, may be the reason for the occurrence of overuse tendinopathy in youth athletes. There is also a mismatch in the growth rate of the muscle-tendon unit relative to that of bone during puberty, in which changes in tendon moment arm do not always remain proportional to the changes in muscle and external moment arm length which can lead to increased load on the tendon with running (O'Brien, 2016). Another concern is that tendon tissue also responds to different kinds of stimulus than muscle. While plyometric activities, such as running and jumping, can result in improved muscle strength, plyometrics do not appear effective in improving tendon stiffness in adults (Bohm et al., 2014). Tendon, on the other hand, seems to preferentially respond to strength training exercises with high loads that strain the tendons over a longer duration than ballistic activities (Arampatzis et al., 2010). If a youth runner does not perform any other type of activity, such as strength training, the tendon might not get the proper stimulus to get larger and stronger, and instead there is a greater risk for developing tendinopathies.

Excessive loading of tendons is considered a risk factor for tendinopathy (Millar et al., 2021). To address the overloading of tendons during running one would have to (1) decrease load through training or technique modifications, or (2) improve the tendon's resistance to load (i.e., stiffness). Compared to adults, children develop lower levels of muscle force at slower rates (Asai and Aoki, 1996; Grosset et al., 2005; Falk et al., 2009; Gillen et al., 2019). Implementing a strength training program for youth runners would address this relative muscle weakness and also improve the tendon's stiffness and, in doing so, improve the rate of force production of the muscle tendon unit (Waugh et al., 2014). This is an area of ongoing research in children.

\section{Sensorimotor Aspects of Running in Adolescents}

The greater vulnerability to foot and ankle injuries of children aged between 10 and 14 years (Lambers et al., 2012; Doherty et al., 2014) is widely related to the challenging phases in motor control development due to the rapidly changing physiological characteristics (e.g., anthropometrics, hormones) (Davies and Rose, 2000). Although most aspects of the association between growth and sensorimotor control are still unknown, there is evidence that basic coordination skills are highly adaptable during childhood and adolescence (Quatman-Yates et al., 2012). This includes phases of quick improvements and steady states, although some individuals may show temporary declines in balance abilities during peak height velocity (Davies and Rose, 2000; John et al., 2019b; Schedler et al., 2019). An indication for the development of sensorimotor control in gait is the long-lasting decline in stride-to-stride variability, which is exceptionally high during the early childhood years and decreases constantly until teenage years (Hausdorff et al., 1999; Petersen et al., 2010; Kraan et al., 2017). A high adaptability of the sensorimotor system to lower extremity balance, strength, power and postural stability (and associated running biomechanics) in the adolescent years is shown in studies using neuromuscular training intervention (Faude et al., 2017; Hopper et al., 2017).

An indication that development of sensorimotor control during childhood may depend on footwear habits is provided by John et al. (2019a). These investigators demonstrated that maturation led to a steady state of balance performance in 11-14 year-old boys who used shoes for sports and recreational activities. Participants of the same age who grew up habitually barefoot, however, continued to increase their balance performance during adolescence (John et al., 2019a). This finding may explain the benefits of habitual barefoot activities regarding a possible reduction of lower limb injury risk in adolescents from Kenya (Aibast et al., 2017). However, the evidence for the influence of footwear on musculoskeletal pain and injuries is limited (Hollander et al., 2017; Francis et al., 2018). Likewise, the evidence regarding the effects of running injury prevention strategies in children or adolescents is scarce. In adult runners, inconsistent findings were reported for the effects of different running shoe properties (insoles, cushioning) (Ryan et al., 2014; Nigg et al., 2015; Hulme et al., 2017). Regardless of the sport, adolescent athletes seem to benefit from neuromuscular training interventions not just for injury prevention but also regarding injurious biomechanics and sensorimotor control (Faude et al., 2017; Hopper et al., 2017). However, future research is needed to confirm or refute these effects in youth running athletes.

\section{DISCUSSION}

It is clear that limited evidence exists on the influence of biomechanics on RRI risk during growth and development in youth runners. Nonetheless participation in runningbased activities has significant health benefits. Running is positively associated with improved movement competencies including stability and control skills 


\section{Risk Factor Considerations for Running-Related Injury (RRI) in the Assessment of the Adolescent Runner}

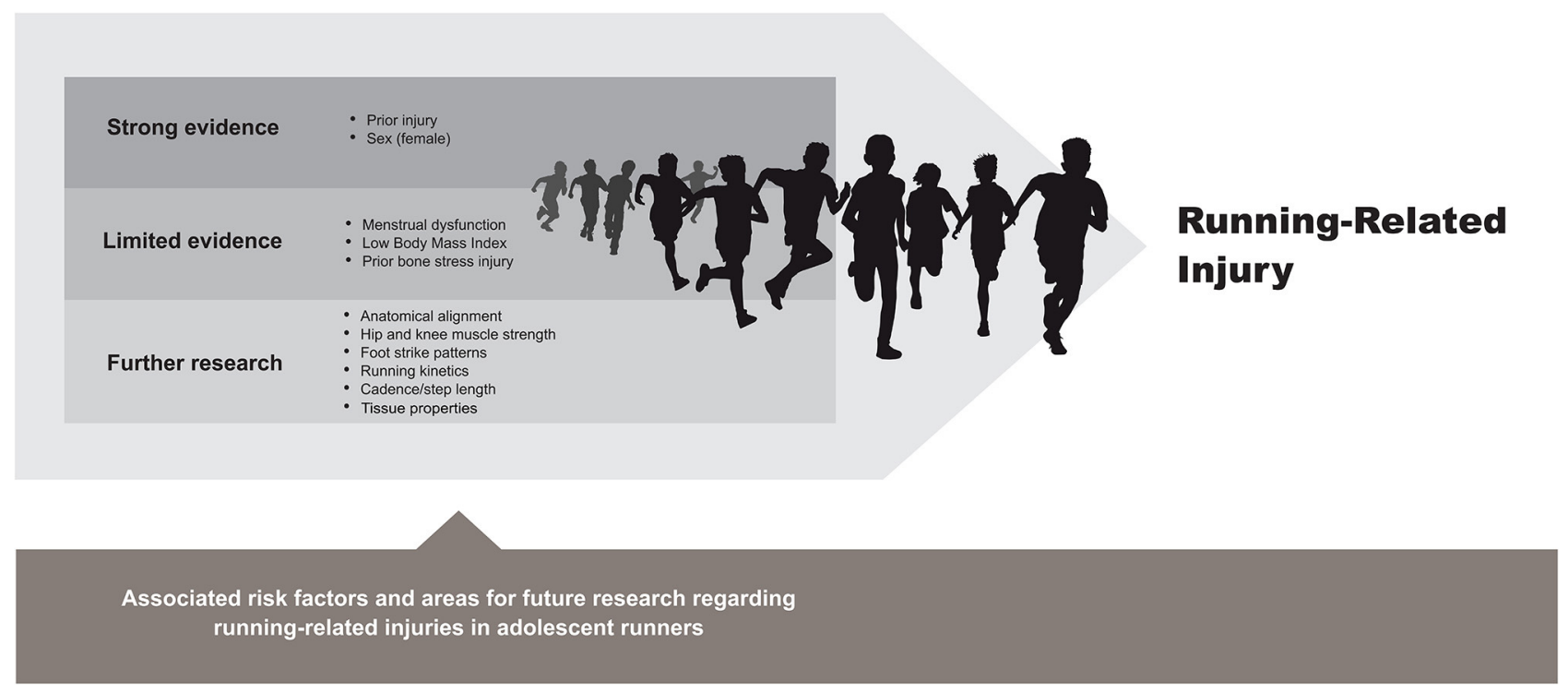

FIGURE 1 | Risk factor considerations for running-related injury (RRI) in the assessment of the adolescent runner.

(Kriemler et al., 2010; Lubans et al., 2010; Krabak et al., 2020). Running can also improve cardiorespiratory fitness while also decreasing the risk of obesity, thereby impacting long-term issues such as heart disease and diabetes (Kriemler et al., 2010; Lubans et al., 2010). Thus, running represents an easy and effective method for youth to meet current exercise guidelines of 60 min or more physical activity per day (Bull et al., 2020).

Unfortunately, there have been no scientific reports to support specific evidence-based training recommendations for youth runners (Krabak et al., 2020; Scheer et al., 2021). Published recommendations regarding appropriate training volumes and distances are mostly based on opinions of healthcare professionals and coaches (Jenny and Armstrong, 2013; Blankson and Brenner, 2016; Finley et al., 2017; Scheer et al., 2021). Youthspecific running programs associated with running clubs (e.g., Boston Athletic Association, Students Run Los Angeles) have attempted to address the risk of injury in these youth running training programs, but more research is needed (Students run LA, 0000; Miller et al., 2018). Despite these limitations, it seems reasonable to suggest that youth participating in a supervised training program are theoretically more likely to be physically and mentally prepared for running events and are potentially at a lower risk for injury and burnout than those youth not participating in supervised training programs (Krabak et al., 2020).

With the goals of reducing overall running-related loads and those specific to the injured tissue, gait retraining is an emerging rehabilitation-specific strategy to modify the biomechanics contributing to injury in the impaired runner. Gait retraining considerations may be deemed appropriate for the injured runner with non-resolving symptoms, following a period of relative rest and reintroduction of gradual increases in running training volume (Davis and Futrell, 2016; Krabak et al., 2016b). If implemented correctly, the demands placed on the injured tissue are reduced thereby promoting recovery and potentially mitigating risk of recurrence. While resistance training increases the load capacity of tissue, the strength gains do not typically improve the running biomechanics associated with injury risk (Willy and Davis, 2011). Several running retraining approaches have been suggested, such as increasing step rate or transitioning to a non-rearfoot strike, and the biomechanical effects of each are well-described in adults (Heiderscheit et al., 2011; Chumanov et al., 2012; Adams et al., 2018; Yong et al., 2018; Napier et al., 2019; Zimmermann and Bakker, 2019). Despite few clinical trials, the findings have been consistently positive in that appropriately applied running retraining improves patient-reported outcomes and injury recovery (Noehren et al., 2011; Willy et al., 2012; Helmhout et al., 2015). For example, increasing step rate or using a non-rearfoot strike improved symptom resolution and return to full running in adults with patellofemoral pain (Roper et al., 2016; Bramah et al., 2019; Dos Santos et al., 2019), likely due to the accompanying reduction in patellofemoral joint loading (Lenhart et al., 2014, 2015). Importantly, running retraining can induce secondary biomechanical changes that must be 
considered, such as an increase in Achilles tendon loading with non-rearfoot strike (Baggaley et al., 2017). As such, selecting an appropriate running retraining approach should not be viewed as one-size-fits-all but instead be based on the individual's injury characteristics, running mechanics, and running-related goals.

To date, no trials among adolescent runners have been reported using running retraining as part of an injury rehabilitation plan. A recent trial found that healthy adolescent runners did not modify their footstrike pattern after 10-week running retraining programs designed to promote a transition to a non-rearfoot strike (González et al., 2021), suggesting unique approaches may be necessary in this population. Nonetheless, given the increased risk of shin pain in high school runners and of BSI in collegiate runners using a lower step rate (Luedke et al., 2016; Kliethermes et al., 2021), running retraining in this population may be considered as part of a comprehensive treatment plan.

Based on current evidence, several factors should be addressed in the youth runner with the goal of preventing or rehabilitating injury. There is strong evidence to support prior injury and sex (i.e., girls) as risk factors for future RRI (Krabak et al., 2020), and more limited evidence to support menstrual dysfunction and low BMI to development of stress fractures (Field et al., 2011; Tenforde et al., 2015). Assessments focused on anatomical alignment, strength or flexibility deficits, footstrike kinematics, running kinetics and neuromuscular control need more robust research, but represent potential opportunities for injury prevention. Furthermore, it should be considered that in recent years a more complex model for injury risk has emerged (Bittencourt et al., 2016). This model described by Bittencourt et al. (2016) is certainly to be taken into consideration for assessing injury risk in youth runner, as these nonbiomechanical and biomechanical factors may interact with each other. Therefore, athletes should be comprehensively clinically

\section{REFERENCES}

Adams, D., Pozzi, F., Willy, R. W., Carrol, A., and Zeni, J. (2018). Altering cadence or vertical oscillation during running: effects on running related injury factors. Int. J. Sports Phys. Ther. 13:633. doi: 10.26603/ijspt20180633

Aibast, H., Okutoyi, P., Sigei, T., Adero, W., Chemjor, D., Ongaro, N., et al. (2017). Foot structure and function in habitually barefoot and shod adolescents in Kenya. Curr. Sports Med. Rep. 16, 448-458. doi: 10.1249/JSR.0000000000000431

Alexander, R. (1990). Three uses for springs in legged locomotion. Int. J. Rob. Res. 9, 53-61. doi: 10.1177/027836499000900205

Alexander, R. M. (2002). Tendon elasticity and muscle function. Comp. Biochem. Physiol. A. Mol. Integr Physiol. 133, 1001-1011. doi: 10.1016/S1095-6433(02)00143-5

Anderson, L. M., Bonanno, D. R., Hart, H. F., and Barton, C. J. (2019). What are the benefits and risks associated with changing foot strike pattern during running? A systematic review and meta-analysis of injury, running economy, and biomechanics. Sports Med. 50, 1-33. doi: 10.1007/s40279-019-01238-y

Arampatzis, A., Peper, A., Bierbaum, S., and Albracht, K. (2010). Plasticity of human Achilles tendon mechanical and morphological properties in response to cyclic strain. J. Biomech. 43, 3073-3079. doi: 10.1016/j.jbiomech.2010.08.014

Asai, H., and Aoki, J. (1996). Force development of dynamic and static contractions in children and adults. Int. J. Sports Med. 17, 170-174. doi: $10.1055 /$ s-2007-972827 screened for the known factors with further interventions, as appropriate (Figure 1).

This perspective article has provided a summary of the current knowledge and future considerations for research in adolescent running biomechanics and injury prevention. Ultimately what is missing are comprehensive longitudinal studies monitoring changes in running biomechanics and associated musculoskeletal tissue. Such data is critical for the effective design of injury prevention and return to running programs that not only foster optimal performance but also promote healthy musculoskeletal development in adolescents.

\section{DATA AVAILABILITY STATEMENT}

The original contributions presented in the study are included in the article, further inquiries can be directed to the corresponding author.

\section{AUTHOR CONTRIBUTIONS}

SM, KG, AG, BH, BK, MR, AT, SW, AZ, and KH: substantial contributions to the conception or design of the work, drafting the work or revising it critically for important intellectual content, provide approval for publication of the content, and agree to be accountable for all aspects of the work in ensuring that questions related to the accuracy or integrity of any part of the work are appropriately investigated and resolved. All authors contributed to the article and approved the submitted version.

\section{ACKNOWLEDGMENTS}

The authors would like to thank Jim Maciukenas of the Indiana University, School of Public Health-Bloomington for his assistance with the graphical design of Figure $\mathbf{1}$.
Baggaley, M., Willy, R., and Meardon, S. (2017). Primary and secondary effects of real-time feedback to reduce vertical loading rate during running. Scand. J. Med. Sci. Sports 27, 501-507. doi: 10.1111/sms.12670

Bahr, R., and Holme, I. (2003). Risk factors for sports injuries-a methodological approach. Br. J. Sports Med. 37, 384-392. doi: 10.1136/bjsm.37.5.384

Barrack, M. T., Fredericson, M., Tenforde, A. S., and Nattiv, A. (2017). Evidence of a cumulative effect for risk factors predicting low bone mass among male adolescent athletes. Br. J. Sports Med. 51, 200-205. doi: 10.1136/bjsports-2016-096698

Barrack, M. T., Gibbs, J. C., De Souza, M. J., Williams, N. I., Nichols, J. F., Rauh, M. J., et al. (2014). Higher incidence of bone stress injuries with increasing female athlete triad-related risk factors: a prospective multisite study of exercising girls and women. Am. J. Sports Med. 42, 949-958. doi: 10.1177/0363546513520295

Beachy, G., Akau, C. K., Martinson, M., and Olderr, T. F. (1997). High school sports injuries: a longitudinal study at Punahou School: 1988 to 1996. Am. J. Sports Med. 25, 675-681. doi: 10.1177/036354659702500515

Beachy, G., and Rauh, M. (2014). Middle school injuries: a 20-year (1988-2008) multisport evaluation. J. Athl. Train. 49, 493-506. doi: 10.4085/1062-6050-49.2.19

Bittencourt, N. F., Meeuwisse, W., Mendonça, L., Nettel-Aguirre, A., Ocarino, J., and Fonseca, S. (2016). Complex systems approach for sports injuries: moving from risk factor identification to injury pattern recognitionnarrative review and new concept. Br. J. Sports Med. 50, 1309-1314. doi: 10.1136/bjsports-2015-095850 
Blankson, K. L., and Brenner, J. S. (2016). Anticipatory guidance for long-distance running in young athletes. Pediatr. Ann. 45, e83-e86. doi: 10.3928/00904481-20160210-01

Bohm, S., Mersmann, F., Tettke, M., Kraft, M., and Arampatzis, A. (2014). Human Achilles tendon plasticity in response to cyclic strain: effect of rate and duration. J. Exp. Biol. 217, 4010-4017. doi: 10.1242/jeb.112268

Bramah, C., Preece, S. J., Gill, N., and Herrington, L. (2019). A 10\% increase in step rate improves running kinematics and clinical outcomes in runners with patellofemoral pain at 4 weeks and 3 months. Am. J. Sports Med. 47, 3406-3413. doi: $10.1177 / 0363546519879693$

Bredeweg, S. W., Kluitenberg, B., Bessem, B., and Buist, I. (2013). Differences in kinetic variables between injured and noninjured novice runners: a prospective cohort study. J. Sci. Med. Sport 16, 205-210. doi: 10.1016/j.jsams.2012.08.002

Bull, F. C., Al-Ansari, S. S., Biddle, S., Borodulin, K., Buman, M. P., Cardon, G., et al. (2020). World Health Organization 2020 guidelines on physical activity and sedentary behaviour. Br. J. Sports Med. 54, 1451-1462. doi: 10.1136/bjsports-2020-102955

Ceyssens, L., Vanelderen, R., Barton, C., Malliaras, P., and Dingenen, B. (2019). Biomechanical risk factors associated with runningrelated injuries: a systematic review. Sports Med. 49, 1095-1115. doi: 10.1007/s40279-019-01110-Z

Chan, Z. Y., Zhang, J. H., Au, I. P., An, W. W., Shum, G. L., Ng, G. Y., et al. (2018). Gait retraining for the reduction of injury occurrence in novice distance runners: 1-year follow-up of a randomized controlled trial. Am. J. Sports Med. 46, 388-395. doi: 10.1177/0363546517736277

Chumanov, E. S., Wille, C. M., Michalski, M. P., and Heiderscheit, B. C. (2012). Changes in muscle activation patterns when running step rate is increased. Gait Posture 36, 231-235. doi: 10.1016/j.gaitpost.2012.02.023

Copenhaver, E. A., and Diamond, A. B. (2017). The value of sleep on athletic performance, injury, and recovery in the young athlete. Pediatr. Ann. 46, e106-e111. doi: 10.3928/19382359-20170221-01

Davies, P. L., and Rose, J. D. (2000). Motor skills of typically developing adolescents: awkwardness or improvement? Phys. Occup. Ther. Pediatr. 20, 19-42. doi: 10.1080/J006v20n01_03

Davis, I. S., Bowser, B. J., and Mullineaux, D. R. (2016). Greater vertical impact loading in female runners with medically diagnosed injuries: a prospective investigation. Br. J. Sports Med. 50, 887-892. doi: 10.1136/bjsports-2015-094579

Davis, I. S., and Futrell, E. (2016). Gait retraining: altering the fingerprint of gait. Phys. Med. Rehabil. Clin. 27, 339-355. doi: 10.1016/j.pmr.2015.09.002

Davis, I. S., Rice, H. M., and Wearing, S. C. (2017). Why forefoot striking in minimal shoes might positively change the course of running injuries. J. Sport Health Sci. 6, 154-161. doi: 10.1016/j.jshs.2017.03.013

De Souza, M. J., Nattiv, A., Joy, E., Misra, M., Williams, N. I., Mallinson, R. J., et al. (2014). 2014 female athlete triad coalition consensus statement on treatment and return to play of the female athlete triad: 1st international conference held in San Francisco, California, May 2012 and 2nd international conference held in Indianapolis, Indiana, May 2013. Br. J. Sports Med. 48, 289-289. doi: 10.1136/bjsports-2013-093218

Doherty, C., Delahunt, E., Caulfield, B., Hertel, J., Ryan, J., and Bleakley, C. (2014). The incidence and prevalence of ankle sprain injury: a systematic review and meta-analysis of prospective epidemiological studies. Sports Med. 44, 123-140. doi: 10.1007/s40279-013-0102-5

Dos Santos, A. F., Nakagawa, T. H., Lessi, G. C., Luz, B. C., Matsuo, H. T., Nakashima, G. Y., et al. (2019). Effects of three gait retraining techniques in runners with patellofemoral pain. Phys. Ther. Sport 36, 92-100. doi: $10.1016 /$ j.ptsp.2019.01.006

Dudley, R. I., Pamukoff, D. N., Lynn, S. K., Kersey, R. D., and Noffal, G. J. (2017). A prospective comparison of lower extremity kinematics and kinetics between injured and non-injured collegiate cross country runners. Hum. Mov. Sci. 52, 197-202. doi: 10.1016/j.humov.2017.02.007

Emery, C. A., Cassidy, J. D., Klassen, T. P., Rosychuk, R. J., and Rowe, B. H. (2005). Effectiveness of a home-based balance-training program in reducing sportsrelated injuries among healthy adolescents: a cluster randomized controlled trial. CMAJ 172, 749-754. doi: 10.1503/cmaj.1040805

Falk, B., Usselman, C., Dotan, R., Brunton, L., Klentrou, P., Shaw, J., et al. (2009). Child-adult differences in muscle strength and activation pattern during isometric elbow flexion and extension. Appl. Physiol. Nutr. Metab. 34, 609-615. doi: $10.1139 / \mathrm{H} 09-020$
Faude, O., Rössler, R., Petushek, E. J., Roth, R., Zahner, L., and Donath, L. (2017). Neuromuscular adaptations to multimodal injury prevention programs in youth sports: a systematic review with meta-analysis of randomized controlled trials. Front. Physiol. 8:791. doi: 10.3389/fphys.2017.00791

Field, A. E., Gordon, C. M., Pierce, L. M., Ramappa, A., and Kocher, M. S. (2011). Prospective study of physical activity and risk of developing a stress fracture among preadolescent and adolescent girls. Arch. Pediatr. Adolesc. Med. 165, 723-728. doi: 10.1001/archpediatrics.2011.34

Finley, P. S., Fountain, J., and Finley, D. P. (2017). Road racing and youth running: cross country coaches' perspectives. Sport J. 19.

Finnoff, J. T., Hall, M. M., Kyle, K., Krause, D. A., Lai, J., and Smith, J. (2011). Hip strength and knee pain in high school runners: a prospective study. $P M R 3$, 792-801. doi: 10.1016/j.pmrj.2011.04.007

Francis, P., Schofield, G., and Mackay, L. (2018). Being barefoot. Prevalence at home, in school and during sport: a cross-sectional survey of 714 New Zealand secondary school boys. J. Foot. Ankle Res. 11:42. doi: 10.1186/s13047-018-0285-y

Fredericson, M., Ngo, J., and Cobb, K. (2005). Effects of ball sports on future risk of stress fracture in runners. Clin. J. Sport Med. 15, 136-141. doi: $10.1097 / 01 . j s m .0000165489 .68997 .60$

Garcia, M. C., Taylor-Haas, J. A., Rauh, M. J., Toland, M. D., and Bazett-Jones, D. M. (2021). Sport specialization in middle-and high-school long-distance runners. J. Athl. Train. doi: 10.4085/462-20. [Epub ahead of print].

Gillen, Z. M., Shoemaker, M. E., McKay, B. D., Bohannon, N. A., Gibson, S. M., and Cramer, J. T. (2019). Muscle strength, size, and neuromuscular function before and during adolescence. Eur. J. Appl. Physiol. 119, 1619-1632. doi: 10.1007/s00421-019-04151-4

González, P. J. C., García-Pinillos, F., López, D. J. M., Linares, A. J. C., Montilla, J. A. P., and Latorre-Román, P. Á. (2021). Effects of a 10-week running-retraining programme on the foot strike pattern of adolescents: a longitudinal intervention study. Gait Posture 83, 147-151. doi: 10.1016/j.gaitpost.2020.09.024

Grosset, J.-F., Mora, I., Lambertz, D., and Perot, C. (2005). Age-related changes in twitch properties of plantar flexor muscles in prepubertal children. Pediatr. Res. 58, 966-970. doi: 10.1203/01.PDR.0000181375.61935.7D

Hamill, J., Palmer, C., and Van Emmerik, R. E. (2012). Coordinative variability and overuse injury. Sports Med. Arthrosc. Rehabil. Ther. Technol. 4, 1-9. doi: $10.1186 / 1758-2555-4-45$

Hausdorff, J., Zemany, L., Peng, C.-K., and Goldberger, A. (1999). Maturation of gait dynamics: stride-to-stride variability and its temporal organization in children. J. Appl. Physiol. 86, 1040-1047. doi: 10.1152/jappl.1999.86.3. 1040

Heiderscheit, B. C., Chumanov, E. S., Michalski, M. P., Wille, C. M., and Ryan, M. B. (2011). Effects of step rate manipulation on joint mechanics during running. Med. Sci. Sports Exerc. 43:296. doi: 10.1249/MSS.0b013e3181ebedf4

Helmhout, P. H., Diebal, A. R., van der Kaaden, L., Harts, C. C., Beutler, A., and Zimmermann, W. O. (2015). The effectiveness of a 6-week intervention program aimed at modifying running style in patients with chronic exertional compartment syndrome: results from a series of case studies. Orthop. J. Sports Med. 3:2325967115575691. doi: 10.1177/2325967115575691

Hoenig, T., Rolvien, T., and Hollander, K. (2020). Footstrike patterns in runners: concepts, classifications, techniques, and implicationsfor runningrelated injuries. Deut. Z Sportmed. 71, 55-61. doi: 10.5960/dzsm.2020.424

Hollander, K., de Villiers, J. E., Venter, R., Sehner, S., Wegscheider, K., Braumann, K. M., et al. (2018). foot strike patterns differ between children and adolescents growing up barefoot vs. shod. Int. J. Sports Med. 39, 97-103. doi: $10.1055 / \mathrm{s}-0043-120344$

Hollander, K., Heidt, C., Babette, C. V. D. Z., Braumann, K. M., and Zech, A. (2017). Long-term effects of habitual barefoot running and walking: a systematic review. Med. Sci. Sports Exerc. 49, 752-762. doi: 10.1249/MSS.0000000000001141

Hollander, K., Johnson, C. D., Outerleys, J., and Davis, I. S. (2021a). Multifactorial determinants of running injury locations in 550 injured recreational runners. Med. Sci. Sports Exerc. 53, 102-107. doi: 10.1249/MSS.0000000000002455

Hollander, K., Rahlf, A. L., Wilke, J., Edler, C., Steib, S., Junge, A., et al. (2021b). Sex-specific differences in running injuries: a systematic review with meta-analysis and meta-regression. Sports Med. 51, 1011-1039. doi: 10.1007/s40279-020-01412-7 
Hopper, A. J., Haff, E. E., Joyce, C., Lloyd, R. S., and Haff, G. G. (2017). Neuromuscular training improves lower extremity biomechanics associated with knee injury during landing in 11-13 year old female netball athletes: a randomized control study. Front. Physiol. 8:883. doi: 10.3389/fphys.2017.00883

Hulme, A., Nielsen, R. O., Timpka, T., Verhagen, E., and Finch, C. (2017). Risk and protective factors for middle-and long-distance running-related injury. Sports Med. 47, 869-886. doi: 10.1007/s40279-016-0636-4

Hulteen, R. M., Smith, J. J., Morgan, P. J., Barnett, L. M., Hallal, P. C., Colyvas, K., et al. (2017). Global participation in sport and leisure-time physical activities: a systematic review and meta-analysis. Prev. Med. 95, 14-25. doi: 10.1016/j.ypmed.2016.11.027

Jenny, S., and Armstrong, T. (2013). Distance running and the Elementary-age child. J. Phys. Edu. Recreation Dance 84, 17-25. doi: 10.1080/07303084.2013.763709

John, C., Hollander, K., Elsabe de Villiers, J., Hamacher, D., Venter, R., and Zech, A. (2019a). The influence of biological maturity on motor performance among habitually barefoot versus habitually shod adolescents. Eur. J. Sport Sci. 19, 621-627. doi: 10.1080/17461391.2018.1543455

John, C., Rahlf, A. L., Hamacher, D., and Zech, A. (2019b). Influence of biological maturity on static and dynamic postural control among male youth soccer players. Gait Posture 68, 18-22. doi: 10.1016/j.gaitpost.2018.10.036

Kelsey, J. L., Bachrach, L. K., Procter-Gray, E., Nieves, J., Greendale, G. A., Sowers, M., et al. (2007). Risk factors for stress fracture among young female cross-country runners. Med. Sci. Sports Exerc. 39, 1457-1463. doi: $10.1249 / \mathrm{mss} .0 \mathrm{~b} 013 \mathrm{e} 318074 \mathrm{e} 54 \mathrm{~b}$

Ker, R., Alexander, R. M., and Bennett, M. (1988). Why are mammalian tendons so thick? J. Zool. 216, 309-324. doi: 10.1111/j.1469-7998.1988.tb02432.x

Kliethermes, S. A., Stiffler-Joachim, M. R., Wille, C. M., Sanfilippo, J. L., Zavala, P., and Heiderscheit, B. C. (2021). Lower step rate is associated with a higher risk of bone stress injury: a prospective study of collegiate cross country runners. Br. J. Sports Med. 55. doi: 10.1136/bjsports-2020-103833

Konow, N., Azizi, E., and Roberts, T. J. (2012). Muscle power attenuation by tendon during energy dissipation. Proc. R. Soc. B, Biol. Sci. 279, 1108-1113. doi: 10.1098/rspb.2011.1435

Kraan, C., Tan, A., and Cornish, K. (2017). The developmental dynamics of gait maturation with a focus on spatiotemporal measures. Gait Posture 51:208-217. doi: 10.1016/j.gaitpost.2016.10.021

Krabak, B. J., Roberts, W. O., Tenforde, A. S., Ackerman, K. E., Adami, P. E., Baggish, A. L., et al. (2020). Youth running consensus statement: minimising risk of injury and illness in youth runners. Br. J. Sports Med. 55, 305-318. doi: 10.1136/bjsports-2020-102518

Krabak, B. J., Snitily, B., and Milani, C. J. (2016a). Running injuries during adolescence and childhood. Phys. Med. Rehabil. Clin. 27, 179-202. doi: 10.1016/j.pmr.2015.08.010

Krabak, B. J., Snitily, B., and Milani, C. J. (2016b). Understanding and treating running injuries in the youth athlete. Curr. Phys. Med. Rehabil. Rep. 4, 161-169. doi: 10.1007/s40141-016-0122-9

Kriemler, S., Zahner, L., Schindler, C., Meyer, U., Hartmann, T., Hebestreit, H., et al. (2010). Effect of school based physical activity programme (KISS) on fitness and adiposity in primary schoolchildren: cluster randomised controlled trial. BMJ 340:c785. doi: 10.1136/bmj.c785

Kubo, K., Ikebukuro, T., Yata, H., Tsunoda, N., and Kanehisa, H. (2010). Time course of changes in muscle and tendon properties during strength training and detraining. J. Strength Cond. Res. 24, 322-331. doi: 10.1519/JSC.0b013e3181c865e2

Kubo, K., Kanehisa, H., Kawakami, Y., and Fukanaga, T. (2001). Growth changes in the elastic properties of human tendon structures. Int. J. Sports Med. 22, 138-143. doi: 10.1055/s-2001-11337

Kuhman, D. J., Paquette, M. R., Peel, S. A., and Melcher, D. A. (2016). Comparison of ankle kinematics and ground reaction forces between prospectively injured and uninjured collegiate cross country runners. Hum. Mov. Sci. 47, 9-15. doi: 10.1016/j.humov.2016.01.013

Lambers, K., Ootes, D., and Ring, D. (2012). Incidence of patients with lower extremity injuries presenting to US emergency departments by anatomic region, disease category, and age. Clin. Orthop. Relat. Res. 470, 284-290. doi: 10.1007/s11999-011-1982-z

Lambertz, D., Mora, I., Grosset, J.-F., and Pérot, C. (2003). Evaluation of musculotendinous stiffness in prepubertal children and adults, taking into account muscle activity. J. Appl. Physiol. 95, 64-72. doi: 10.1152/japplphysiol.00885.2002

Latorre Roman, P. A., Redondo Balboa, F., Parraga Montilla, J., Soto Hermoso, V. M., Consuegra Gonzalez, P. J., and Garcia Pinillos, F. (2019). Analysis of foot strike pattern, rearfoot dynamic and foot rotation over childhood. A crosssectional study. J. Sports Sci. 37, 477-483. doi: 10.1080/02640414.2018.1507237

Lenhart, R. L., Smith, C. R., Vignos, M. F., Kaiser, J., Heiderscheit, B. C., and Thelen, D. G. (2015). Influence of step rate and quadriceps load distribution on patellofemoral cartilage contact pressures during running. J. Biomech. 48, 2871-2878. doi: 10.1016/j.jbiomech.2015.04.036

Lenhart, R. L., Thelen, D. G., Wille, C. M., Chumanov, E. S., and Heiderscheit, B. C. (2014). Increasing running step rate reduces patellofemoral joint forces. Med. Sci. Sports Exerc. 46:557. doi: 10.1249/MSS.0b013e3182a78c3a

Lieberman, D. E., Venkadesan, M., Werbel, W. A., Daoud, A. I., D'andrea, S. Davis, I. S., et al. (2010). Foot strike patterns and collision forces in habitually barefoot versus shod runners. Nature 463, 531-535. doi: 10.1038/nature08723

Lloyd, R. S., Oliver, J. L., Faigenbaum, A. D., Myer, G. D., and Croix, M. B. D. S. (2014). Chronological age vs. biological maturation: implications for exercise programming in youth. J. Strength Cond. Res. 28, 1454-1464. doi: 10.1519/JSC.0000000000000391

Lubans, D. R., Morgan, P. J., Cliff, D. P., Barnett, L. M., and Okely, A. D. (2010). Fundamental movement skills in children and adolescents. Sports Med. 40, 1019-1035. doi: 10.2165/11536850-000000000-00000

Luedke, L. E., Heiderscheit, B. C., Williams, D., and Rauh, M. J. (2016). Influence of step rate on shin injury and anterior knee pain in high school runners. Med. Sci. Sports Exerc. 48, 1244-1250. doi: 10.1249/MSS.0000000000000890

Luedke, L. E., Heiderscheit, B. C., Williams, D. B., and Rauh, M. J. (2015). Association of isometric strength of hip and knee muscles with injury risk in high school cross country runners. Int. J. Sports Phys. Ther. 10:868.

Malina, R. M. (1994). Physical growth and biological maturation of young athletes. Exerc. Sport Sci. Rev. 22, 280-284. doi: 10.1249/00003677-199401000-00012

Meeuwisse, W. H. (1994). Assessing Causation in Sport Injury: A Multifactorial Model. Philadelphia, PA: LWW. doi: 10.1097/00042752-199407000-00004

Mehl, A. J., Nelson, N. G., and McKenzie, L. B. (2011). Running-related injuries in school-age children and adolescents treated in emergency departments from 1994 through 2007. Clin. Pediatr. (Phila) 50, 126-132. doi: 10.1177/0009922810384719

Mersmann, F., Bohm, S., and Arampatzis, A. (2017). Imbalances in the development of muscle and tendon as risk factor for tendinopathies in youth athletes: a review of current evidence and concepts of prevention. Front. Physiol. 8:987. doi: 10.3389/fphys.2017.00987

Messier, S. P., Martin, D. F., Mihalko, S. L., Ip, E., DeVita, P., Cannon, D. W., et al. (2018). A 2-year prospective cohort study of overuse running injuries: the runners and injury longitudinal study (TRAILS). Am. J. Sports Med. 46, 2211-2221. doi: $10.1177 / 0363546518773755$

Meyers, R. W., Oliver, J. L., Hughes, M. G., Lloyd, R. S., and Cronin, J. B. (2017). Influence of age, maturity, and body size on the spatiotemporal determinants of maximal sprint speed in boys. $J$. Strength Cond. Res. 31, 1009-1016. doi: 10.1519/JSC.00000000000 01310

Milgrom, C., Simkin, A., Eldad, A., Nyska, M., and Finestone, A. (2000). Using bone's adaptation ability to lower the incidence of stress fractures. Am. J. Sports Med. 28, 245-251. doi: 10.1177/03635465000280021701

Millar, N. L., Silbernagel, K. G., Thorborg, K., Kirwan, P. D., Galatz, L. M., Abrams, G. D., et al. (2021). Tendinopathy. Nat. Rev. Dis. Primers 7, 1-21. doi: 10.1038/s41572-021-00251-8

Miller, E., Goldman, J., Beck, J., Runestad, S., Serpa, R., Sangiorgio, S., et al. (2018). Is marathon training safe for adolescents? AMSSM research Podium presentations. Clin. J. Sport Med. 28, 239-248. doi: 10.1097/JSM.0000000000000591

Mogi, Y. (2020). The effects of growth on structural properties of the Achilles and Patellar tendons: a cross-sectional study. Physiol. Rep. 8:e14544. doi: 10.14814/phy2.14544

Mountjoy, M., Sundgot-Borgen, J., Burke, L., Ackerman, K. E., Blauwet, C., Constantini, N., et al. (2018). International Olympic Committee (IOC) consensus statement on relative energy deficiency in sport (RED-S): 2018 update. Int. J. Sport Nutr. Exerc. Metab. 28, 316-331. doi: 10.1123/ijsnem.2018-0136 
Mucha, M. D., Caldwell, W., Schlueter, E. L., Walters, C., and Hassen, A. (2017). Hip abductor strength and lower extremity running related injury in distance runners: a systematic review. J. Sci. Med. Sport 20, 349-355. doi: 10.1016/j.jsams.2016.09.002

Napier, C., MacLean, C. L., Maurer, J., Taunton, J. E., and Hunt, M. A. (2019). Real-time biofeedback of performance to reduce braking forces associated with running-related injury: An exploratory study. J. Orthop. Sports Phys. Ther. 49, 136-144. doi: 10.2519/jospt.2019.8587

Nigg, B. M., Baltich, J., Hoerzer, S., and Enders, H. (2015). Running shoes and running injuries: mythbusting and a proposal for two new paradigms: 'preferred movement path'and 'comfort filter'. Br. J. Sports Med. 49, 1290-1294. doi: 10.1136/bjsports-2015-095054

Noehren, B., Scholz, J., and Davis, I. (2011). The effect of real-time gait retraining on hip kinematics, pain and function in subjects with patellofemoral pain syndrome. Br. J. Sports Med. 45, 691-696. doi: 10.1136/bjsm.2009.069112

O'Brien, T. D. (2016). Musculoskeletal proportionality, biomechanical considerations and their contribution to movement in adults and children. Pediatr. Exerc. Sci. 28, 210-216 doi: 10.1123/pes.2015-0263

O’Brien, T. D., Reeves, N. D., Baltzopoulos, V., Jones, D. A., and Maganaris, C. N. (2010). Muscle-tendon structure and dimensions in adults and children. J. Anat. 216, 631-642. doi: 10.1111/j.1469-7580.2010.01218.x

Petersen, T. H., Kliim-Due, M., Farmer, S. F., and Nielsen, J. B. (2010). Childhood development of common drive to a human leg muscle during ankle dorsiflexion and gait. J. Physiol. 588, 4387-4400. doi: 10.1113/jphysiol.2010.195735

Plisky, M., Rauh, M., Heiderscheit, B., Underwood, F., and Tank, R. (2007). An epidemiological investigation of medial tibial stress syndrome among high school cross-country runners. J. Orthop. Sports Phys. Ther. 37, 40-47. doi: $10.2519 /$ jospt.2007.2343

Post, E. G., Trigsted, S. M., Riekena, J. W., Hetzel, S., McGuine, T. A., Brooks, M. A., et al. (2017). The association of sport specialization and training volume with injury history in youth athletes. Am. J. Sports Med. 45, 1405-1412. doi: $10.1177 / 0363546517690848$

Quatman-Yates, C. C., Quatman, C. E., Meszaros, A. J., Paterno, M. V., and Hewett, T. E. (2012). A systematic review of sensorimotor function during adolescence: a developmental stage of increased motor awkwardness? Br. J. Sports Med. 46, 649-655. doi: 10.1136/bjsm.2010.079616

Rauh, M., Macera, C., and Marshall, S. (2011). Applied Sports Injury Epidemiology. Athletic and Sport Issues in Musculoskeletal Rehabilitation. St Louis, MO: Saunders, 730-772.

Rauh, M. J. (2014). Summer training factors and risk of musculoskeletal injury among high school cross-country runners. J. Orthop. Sports Phys. Ther. 44, 793-804. doi: 10.2519/jospt.2014.5378

Rauh, M. J. (2018). Leg-length inequality and running-related injury among high school runners. Int. J. Sports Phys. Ther. 13:643. doi: 10.26603/ijspt20180643

Rauh, M. J., Barrack, M., and Nichols, J. F. (2014). Associations between the female athlete triad and injury among high school runners. Int. J. Sports Phys. Ther. 9:948.

Rauh, M. J., Koepsell, T. D., Rivara, F. P., Margherita, A. J., and Rice, S. G. (2006). Epidemiology of musculoskeletal injuries among high school cross-country runners. Am. J. Epidemiol. 163, 151-159. doi: 10.1093/aje/kwj022

Rauh, M. J., Koepsell, T. D., Rivara, F. P., Rice, S. G., and Margherita, A. J. (2007). Quadriceps angle and risk of injury among high school cross-country runners. J. Orthop. Sports Phys. Ther. 37, 725-733. doi: 10.2519/jospt.2007.2453

Rauh, M. J., Margherita, A. J., Rice, S. G., Koepsell, T. D., and Rivara, F. P. (2000). High school cross country running injuries: a longitudinal study. Clin. J. Sport Med. 10, 110-116. doi: 10.1097/00042752-200004000-00005

Rauh, M. J., Tenforde, A. S., Barrack, M. T., Rosenthal, M. D., and Nichols, J. F. (2018). Associations between sport specialization, running-related injury, and menstrual dysfunction among high school distance runners. Athl. Train. Sports Health Care 10, 260-269. doi: 10.3928/19425864-20180918-01

Reinking, M. F., Austin, T. M., and Hayes, A. M. (2010). Risk factors for selfreported exercise-related leg pain in high school cross-country athletes. J. Athl. Train. 45, 51-57. doi: 10.4085/1062-6050-45.1.51

Richmond, S. A., Kang, J., Doyle-Baker, P. K., Nettel-Aguirre, A., and Emery, C. A. (2016). A school-based injury prevention program to reduce sport injury risk and improve healthy outcomes in youth: a pilot cluster-randomized controlled trial. Clin. J. Sport Med. 26, 291-298. doi: 10.1097/JSM.00000000000 00261
Roberts, T. J., and Azizi, E. (2010). The series-elastic shock absorber: tendons attenuate muscle power during eccentric actions. J. Appl. Physiol. 109, 396-404. doi: 10.1152/japplphysiol.01272.2009

Roper, J. L., Harding, E. M., Doerfler, D., Dexter, J. G., Kravitz, L., Dufek, J. S., et al. (2016). The effects of gait retraining in runners with patellofemoral pain: a randomized trial. Clin. Biomech. 35, 14-22. doi: 10.1016/j.clinbiomech.2016.03.010

Rössler, R., Donath, L., Verhagen, E., Junge, A., Schweizer, T., and Faude, O. (2014). Exercise-based injury prevention in child and adolescent sport: a systematic review and meta-analysis. Sports Med. 44, 1733-1748. doi: 10.1007/s40279-014-0234-2

Rumpf, M. C., Cronin, J. B., Oliver, J., and Hughes, M. (2015). Kinematics and kinetics of maximum running speed in youth across maturity. Pediatr. Exerc. Sci. 27, 277-284. doi: 10.1123/pes.2014-0064

Ryan, M., Elashi, M., Newsham-West, R., and Taunton, J. (2014). Examining injury risk and pain perception in runners using minimalist footwear. Br. J. Sports Med. 48, 1257-1262. doi: 10.1136/bjsports-2012-092061

Schedler, S., Kiss, R., and Muehlbauer, T. (2019). Age and sex differences in human balance performance from 6-18 years of age: a systematic review and meta-analysis. PLoS ONE 14:e0214434. doi: 10.1371/journal.pone.0214434

Scheer, V., Costa, R. J. S., Doutreleau, S., Knechtle, B., Nikolaidis, P. T., Roberts, W. O., et al. (2021). Recommendations on youth participation in ultraendurance running events: a consensus statement. Sports Med. 51, 1123-1135. doi: 10.1007/s40279-021-01441-w

Schepens, B., Willems, P., and Cavagna, G. (1998). The mechanics of running in children. J. Physiol. 509 (Pt 3):927. doi: 10.1111/j.1469-7793.1998.927bm.x

Sonneville, K. R., Gordon, C. M., Kocher, M. S., Pierce, L. M., Ramappa, A., and Field, A. E. (2012). Vitamin D, calcium, and dairy intakes and stress fractures among female adolescents. Arch. Pediatr. Adolesc. Med. 166, 595-600. doi: 10.1001/archpediatrics.2012.5

Stearne, S. M., Alderson, J. A., Green, B. A., Donnelly, C. J., and Rubenson, J. (2014). Joint kinetics in rearfoot versus forefoot running: implications of switching technique. Med. Sci. Sports Exerc. 46, 1578-1587. doi: 10.1249/MSS.0000000000000254

Stiffler-Joachim, M. R., Wille, C. M., Kliethermes, S. A., Johnston, W., and Heiderscheit, B. (2019). Foot angle and loading rate during running demonstrate a nonlinear relationship. Med. Sci. Sports Exerc. 51, 2067-2072. doi: 10.1249/MSS.0000000000002023

Students run LA. Available online at: https://www.srla.org/ (accessed February 2, 2021).

Taddei, U. T., Matias, A. B., Duarte, M., and Sacco, I. C. (2020). Foot core training to prevent running-related injuries: a survival analysis of a singleblind, randomized controlled trial. Am. J. Sports Med. 48, 3610-3619. doi: 10.1177/0363546520969205

Tenforde, A., DeLuca, S., Wu, A., Ke, A., Lewis, M., Rauh, M., et al. (2021). Prevalence and factors associated with bone stress injury in middle school runners. $P M$ R. doi: 10.1002/pmrj.12673. [Epub ahead of print].

Tenforde, A. S., Beauchesne, A. R., Borg-Stein, J., Hollander, K., McInnis, K., Kotler, D., et al. (2020). Awareness and comfort treating the female athlete triad and relative energy deficency in sport among healthcare p-roviders. Dtsch $Z$ Sportmed. 71, 76-80. doi: 10.5960/dzsm.2020.422

Tenforde, A. S., Borgstrom, H. E., Outerleys, J., and Davis, I. S. (2019). Is cadence related to leg length and load rate? J. Orthop. Sports Phys. Ther. 49, 280-283. doi: 10.2519/jospt.2019.8420

Tenforde, A. S., and Fredericson, M. (2011). Influence of sports participation on bone health in the young athlete: a review of the literature. $P M R 3,861-867$. doi: 10.1016/j.pmrj.2011.05.019

Tenforde, A. S., Fredericson, M., Sayres, L. C., Cutti, P., and Sainani, K. L. (2015). Identifying sex-specific risk factors for low bone mineral density in adolescent runners. Am. J. Sports Med. 43, 1494-1504. doi: 10.1177/0363546515572142

Tenforde, A. S., Sayres, L. C., McCurdy, M. L., Collado, H., Sainani, K. L., and Fredericson, M. (2011). Overuse injuries in high school runners: lifetime prevalence and prevention strategies. $P M R$ 3, 125-131. doi: 10.1016/j.pmrj.2010.09.009

Tenforde, A. S., Sayres, L. C., McCurdy, M. L., Sainani, K. L., and Fredericson, M. (2013). Identifying sex-specific risk factors for stress fractures in adolescent runners. Med. Sci. Sports Exerc. 45, 1843-1851. doi: 10.1249/MSS.0b013e3182963d75 
Thijs, Y., Pattyn, E., Van Tiggelen, D., Rombaut, L., and Witvrouw, E. (2011). Is hip muscle weakness a predisposing factor for patellofemoral pain in female novice runners? A prospective study. Am. J. Sports Med. 39, 1877-1882. doi: 10.1177/0363546511407617

Tirabassi, J., Brou, L., Khodaee, M., Lefort, R., Fields, S. K., and Comstock, R. D. (2016). Epidemiology of high school sports-related injuries resulting in medical disqualification: 2005-2006 through 2013-2014 academic years. Am. J. Sports Med. 44, 2925-2932. doi: 10.1177/0363546516644604

Toresdahl, B. G., McElheny, K., Metzl, J., Ammerman, B., Chang, B., and Kinderknecht, J. (2020). A randomized study of a strength training program to prevent injuries in runners of the New York City Marathon. Sports Health 12, 74-79. doi: 10.1177/1941738119877180

United States track and field (2020). Available online at: https://www.usatf.org/ resources/statistics/records/national-records (accessed February 2, 2021).

Warr, B. J., Fellin, R. E., Sauer, S. G., Goss, D. L., Frykman, P. N., and Seay, J. F. (2015). Characterization of foot-strike patterns: lack of an association with injuries or performance in soldiers. Mil. Med. 180, 830-834. doi: 10.7205/MILMED-D-14-00220

Waugh, C., Blazevich, A., Fath, F., and Korff, T. (2012). Age-related changes in mechanical properties of the Achilles tendon. J. Anat. 220, 144-155. doi: 10.1111/j.1469-7580.2011.01461.x

Waugh, C. M., Korff, T., Fath, F., and Blazevich, A. J. (2014). Effects of resistance training on tendon mechanical properties and rapid force production in prepubertal children. J. Appl. Physiol. 117, 257-266. doi: 10.1152/japplphysiol.00325.2014

Willy, R. W., and Davis, I. S. (2011). The effect of a hip-strengthening program on mechanics during running and during a single-leg squat. J. Orthop. Sports Phys. Ther. 41, 625-632. doi: 10.2519/jospt.2011.3470

Willy, R. W., Scholz, J. P., and Davis, I. S. (2012). Mirror gait retraining for the treatment of patellofemoral pain in female runners. Clin. Biomech. 27, 1045-1051. doi: 10.1016/j.clinbiomech.2012.07.011

World Health Organization (2018). Adolescent Mental Health. Available online at: https://wwwwhoint/mental_health/maternal-child/adolescent/en/ (accessed February 2, 2021).

Wu, A., Rauh, M., DeLuca, S., Lewis, M., Ackerman, K., Barrack, M., et al. (2021). Running related injuries in middle school cross country runners: prevalence and characteristics of common injuries. PM R. doi: 10.1002/pmrj.12649. [Epub ahead of print].

Yagi, S., Muneta, T., and Sekiya, I. (2013). Incidence and risk factors for medial tibial stress syndrome and tibial stress fracture in high school runners. Knee Surg. Sports Traumatol. Arthrosc. 21, 556-563. doi: 10.1007/s00167-0122160-x

Yong, J. R., Silder, A., Montgomery, K. L., Fredericson, M., and Delp, S. L. (2018). Acute changes in foot strike pattern and cadence affect running parameters associated with tibial stress fractures. J. Biomech. 76, 1-7. doi: 10.1016/j.jbiomech.2018.05.017

Zadpoor, A. A., and Nikooyan, A. A. (2011). The relationship between lowerextremity stress fractures and the ground reaction force: a systematic review. Clin. Biomech. 26, 23-28. doi: 10.1016/j.clinbiomech.2010.08.005

Zimmermann, W. O., and Bakker, E. (2019). Reducing vertical ground reaction forces: the relative importance of three gait retraining cues. Clin. Biomech. 69, 16-20. doi: 10.1016/j.clinbiomech.2019.06.014

Conflict of Interest: The authors declare that the research was conducted in the absence of any commercial or financial relationships that could be construed as a potential conflict of interest.

Publisher's Note: All claims expressed in this article are solely those of the authors and do not necessarily represent those of their affiliated organizations, or those of the publisher, the editors and the reviewers. Any product that may be evaluated in this article, or claim that may be made by its manufacturer, is not guaranteed or endorsed by the publisher.

Copyright (c) 2021 McSweeney, Grävare Silbernagel, Gruber, Heiderscheit, Krabak, Rauh, Tenforde, Wearing, Zech and Hollander. This is an open-access article distributed under the terms of the Creative Commons Attribution License (CC BY). The use, distribution or reproduction in other forums is permitted, provided the original author(s) and the copyright owner(s) are credited and that the original publication in this journal is cited, in accordance with accepted academic practice. No use, distribution or reproduction is permitted which does not comply with these terms. 